\section{Degradation Kinetics of Polycarbonate Composites: Kinetic Parameters and Artificial Neural Network}

\author{
S. J. Charde, ${ }^{a}$ S. S. Sonawane, ${ }^{a, *}$ S. H. Sonawane, ${ }^{\text {b }}$ and N. G. Shimpi ${ }^{c}$ \\ aDepartment of Chemical Engineering, Visvesvaraya National Institute \\ of Technology (VNIT), Nagpur, India 440010 \\ bepartment of Chemical Engineering, NIT Warangal \\ 'Department of Chemistry, University of Mumbai, Mumbai
}

doi: 10.15255/CABEQ.2017.1173

Original scientific paper

Received: June 2, 2017

Accepted: May 25, 2018

In order to design a reactor, kinetics of degradation of polycarbonate $/ \mathrm{CaCO}_{3} \mathrm{com}$ posites was investigated here by thermogravimetric analysis (TGA), applying model-free and modelistic methods together, to obtain $E, A, \Delta S^{*}, \Delta H^{*}$ and $\Delta G^{*}$ (kinetic parameters). The system was tested with all the mechanisms available using non-isothermal modelistic method (Coats-Redfern). This approach allowed choosing the models, which are otherwise difficult to decide upon simply based on regression fit methods. The mechanism proposed was a simple $\mathrm{n}^{\text {th }}$ order. Application of artificial neural network supported in designing a neural network could lead to a quick determination of kinetic parameters.

Keywords:

kinetics, non-isothermal degradation, polycarbonate, Artificial Neural Network

\section{Introduction}

Polycarbonate (PC) is an engineering polymer, and second largest in consumption being used extensively in the areas of electronics, construction, automotive, aircraft industry, compact discs, food containers, packaging, and medical devices. The production rate of PC worldwide grew to around 4.5 million metric tons by the end of $2016^{1}$. Out of the total PC production, the construction industry consumes the second largest portion of the polycarbonate $^{2}$. PC is the most widely used polymer due to its high impact strength, high optical transparency, and good thermal stability; however, it needs improvement in the area of tribology and rheology. In order to improve its properties, PC is being reinforced with nanofillers ${ }^{3-5}$ and this research again adds to the growing demand for PC. These applications lead to very high consumption and finally high accumulation of used polycarbonate as waste. The disposal of PC waste, having high weight-tovolume ratios, imposes an environmental hazard because these plastics are non-biodegradable. Solid waste disposal is achieved using landfilling and incineration, but landfilling is not possible in the case of plastics ${ }^{6-9}$, and incineration results in the production of toxic gases, such as flue gas, and acid and heavy metals leading to air pollution ${ }^{10-12}$. The recycling of plastic waste is a better option ${ }^{13,14}$. To transform the polymer waste into useful, low molecular

*Dr. Shriram S. Sonawane: Tel: +91 7122801562 ,

Fax no: +91 712-2221562, E-mail: shriramsonawane@gmail.com weight hydrocarbons, clean hydrocarbons, fuels, gasoline, or other valuable lubricants, thermal or catalytic degradation can prove useful. Pyrolytic degradation of polymers in the absence of oxygen gives a mixture of hydrocarbons $s^{6,8,10-12}$. Literature provides an insight into the key products of pyrolytic degradation of polycarbonate, such as $\mathrm{CH}_{4}, \mathrm{CO}$, $\mathrm{CO}_{2}, \mathrm{H}_{2} \mathrm{O}$ and other hydrocarbons like ketones, aldehydes, and carbonyls that exhibit low molecular weight ${ }^{15}$. Thermal analysis using thermogravimetric analyzer (TGA) plays an important role in studying the overall kinetics by assessing the alteration in mass with time, providing well controlled conditions ${ }^{16,17}$. Frequent studies focused on understanding PC degradation have been carried out using Py-GC, TG-FTIR or TG-MS ${ }^{15,18}$. Currently, the two most important methods used in studying degradation kinetics are model-free and modelistic techniques. These two approaches propose a number of advantages but have limitations when applied for real cases since they are based on several assumptions. Model-free methods cannot be used for prediction of the reaction mechanism. If we consider the case of successive and parallel reactions, although isoconversional supposition is easy to implement, it is not always satisfied ${ }^{19,20}$. With modelistic techniques it is possible to describe the reaction model that can give an idea about the process mechanism; however, its application to complex processes is not feasible because the reaction scheme is dependent on individual selection ${ }^{21}$. Therefore, a combined use of model-free and modelistic technique helps to eliminate some of the disadvantages, and the combina- 
tion of advantages leads to the best reaction mecha$\operatorname{nism}^{22,23}$

In addition to these methods, artificial neural network (ANN) is another tool useful for predicting kinetic parameters. It is a powerful computing technique useful in predicting the properties of materials using a certain amount of experimental results ${ }^{24}$. It finds applications in modelling the properties of various materials, and is being used rigorously in the field of materials science ${ }^{25-28}$. ANN can be used to analyse and explore the relationship between experimental inputs and outputs to study the behavior of material properties. It is possible to develop a generalized model even if the output variables are nonlinear functions of input variables ${ }^{25}$.

A literature survey reveals that the ANN approach has been used to evaluate thermodynamic and kinetic parameters, and could be successfully applied for obtaining filtered signals from calorimeter $^{29}$. In another development, it was established that ANN was applied for the prediction of kinetic parameters of carbon fiber reinforced carbon composites using the experimental results from thermogravimetric analyzer ${ }^{30}$. Kinetic parameter prediction for biomass oxidation is one of the recent works done using $\mathrm{ANN}^{31}$.

In a similar study, an ANN tool, radial basis functional network, was employed for the case of polymer-clay/silica hybrid nanocomposites to predict the thermal and mechanical properties, and concluded that such tools are useful in the prediction of properties of nanocomposites without actual manufacturing ${ }^{32}$. In a recent development, ANN models were generated to obtain thermoanalytical signals very similar to experimental ones using various combinations of kinetic parameters and reaction model type ${ }^{33}$. It has thus been revealed that ANN offers several advantages over conventional modelling techniques because it is not based upon assumptions concerning kinetic model, and requires no kinetic interval. It is extremely capable of resisting the noisy signals ${ }^{29}$.

It has been observed that the combined use of model-free and modelistic techniques might result in parameter interdependency, also known as the kinetic compensation effect ${ }^{34}$. On the other hand, artificial neural network (ANN) can predict kinetic triplet parameters independently unlike the modelistic technique as it is not based on the isoconversional norm ${ }^{33}$.

This is a unique attempt to determine all the kinetic and thermodynamic parameters using model-free and modelistic methods together for the polycarbonate nanocomposites and prediction of these parameters independently using artificial neural network.

\section{Materials and methods}

\section{Materials}

Polycarbonate (MAKROLON® 2407) was obtained from Bayer Material Science Pvt. Ltd., Mumbai, India. It is a general purpose, low viscosity, UV stabilized grade with MVR $\left(300{ }^{\circ} \mathrm{C} / 1.2 \mathrm{~kg}\right) 19$ $\mathrm{cm}^{3} / 10 \mathrm{~min}$ and melt temperature in the range 280 $320{ }^{\circ} \mathrm{C} . \mathrm{PC} / \mathrm{CaCO}_{3}$ nanocomposites were synthesized via melt extrusion using HAAKE Minilab II Micro Compounder. $\mathrm{CaCO}_{3}$ nanoparticles were obtained using the process as described in a previous work $^{35}$. Prior to mixing, the PC pellets were dried at $80{ }^{\circ} \mathrm{C}$ for 12 hours. Three different wt.\% loading of $\mathrm{CaCO}_{3}$ nanoparticles were added to $\mathrm{PC}$ to obtain $\mathrm{PC} / \mathrm{CaCO}_{3}$ nanocomposites (PCC). The compounder was of $5 \mathrm{~g}$ or $7 \mathrm{~cm}^{3}$ capacity, and had two conical counter-rotating screws with a bypass pathway for the flow of material, which allowed for proper dispersion. The countercurrent screw arrangement and 3-minute recycling ensured proper mixing of nanoparticles into the polycarbonate matrix. The processing temperature in the compounder was maintained at $280{ }^{\circ} \mathrm{C}$, and rotating speed of countercurrent conical extruders was maintained at 100 $\mathrm{rpm}$. The injector was maintained at $310{ }^{\circ} \mathrm{C}$, and, molder at $145^{\circ} \mathrm{C}$. The molding pressure was about 900 bars for 7 seconds, with a post pressure of 650 bars for 5 seconds. All these parameters were finalized after a number of trials.

\section{Characterization methods}

TGA

Thermogravimetric analysis is a technique where thermal properties are determined by measuring physical and chemical properties as a function of temperature at a constant heating rate, or time. Thermogravimetric analysis was performed on a TG 6300 type analyzer (SII Nanotechnology Incorporation, Japan) exposed to inert $\left(\mathrm{N}_{2}\right)$ atmosphere at a constant rate of $60-100 \mathrm{~mL} \mathrm{~min}^{-1}$. The kinetic study was carried out using a definite amount of sample $(5-10 \mathrm{mg})$, dried at $105^{\circ} \mathrm{C}$ for 1 hour, and heating from $30{ }^{\circ} \mathrm{C}$ to $900{ }^{\circ} \mathrm{C}$ at different heating rates, $5,10,15,20^{\circ} \mathrm{C} \mathrm{min}{ }^{-1}$ under inert atmosphere. The use of purge gas removes the volatiles that are generated during degradation.

\section{Kinetic analysis}

A model free and modelistic approach is being used in this work to obtain all the kinetic parameters. The model-free method was used firstly to obtain a preliminary idea of the apparent activation energy value followed by the modelistic method. The values were then compared to each other and thus finalized. A number of model-free methods 
mentioned in the literature are Flynn-Wall-Ozawa (FWO) method, Kissinger-Akahira-Sunose (KAS), Friedman method, and Kissinger-Peak method ${ }^{22}$.

The polymer pyrolysis reaction follows a solid-state reaction, and degree of conversion $\alpha$ decides the rate, as given by Equation (1):

$$
\alpha=\frac{m_{0}-m_{i}}{m_{0}-m_{f}}
$$

where $m_{0}$ is the initial mass, $m_{f}$ is the final mass, and $m_{i}$ is mass at any time t. The fundamental equation of degradation kinetics can be described by Equation $(2)^{36-39}$

$$
\frac{\mathrm{d} \alpha}{\mathrm{d} t}=k(T) f(\alpha)
$$

where, $f(\alpha)$ and $k(T)$ represent conversion and the temperature function, respectively. $k$ is the temperature dependent reaction constant, which is defined by the Arrhenius equation as given by Equation (3):

$$
k=\exp \left[-\frac{E}{R T}\right]
$$

where, $A, T, R$, and $E$ are the pre-exponential factor, absolute temperature, universal gas constant, and activation energy of the process, respectively. Rearrangement of Equation (2) after substitution of Equation (3) into (2) results in Equation (4):

$$
\frac{\mathrm{d} \alpha}{\mathrm{d} t}=A \exp \left[-\frac{E}{R T}\right] f(\alpha)
$$

In the non-isothermal case, in order to raise the temperature, a heating rate $(q)$ is employed, as given by Equation (5)

$$
\frac{\mathrm{d} T}{\mathrm{~d} t}=q=\text { constant }
$$

Therefore, Equation (6):

$$
\frac{\mathrm{d} \alpha}{\mathrm{d} t}=\frac{A}{q} \exp \left[-\frac{E}{R T}\right] f(\alpha)
$$

We used the Kissinger-Peak method, which assumes that the maximum reaction rate corresponds to the peak temperature $\left(T_{p}\right)$ obtained from DTG peak. The Kissinger-Peak equation ${ }^{40}$ is given below, Equation (7):

$$
\ln \left[\frac{\beta}{T_{p}^{2}}\right]=-\frac{E}{R T_{p}}+\ln \left[\frac{A R}{E}\right]
$$

A plot of $\ln \left[\frac{\beta}{T_{p}^{2}}\right]$ against $1 / T_{p}$ gives a straight line. The slope of this line gives activation energy $(E)$.
The modelistic methods use $\alpha$-temperature curves in which the models are fitted and checked, and at the same time the activation energy $E$, pre-exponential factor $A$, and mechanism $n$ of reaction are determined.

For a solid-state reaction, the conversion function $f(\alpha)$ and the reaction mechanism are related, as given by Equation (8). The reaction mechanism by model-free method can be decided based on this conversion function.

$$
f(\alpha)=\alpha^{m}(1-\alpha)^{n}[-\ln (1-\alpha)]^{p}
$$

where, exponent factors $m, n$, and $p$ are achieved empirically so that one of them is always zero ${ }^{39,41}$.

After substituting the values in Equation (8) and separating the variables, the final form is integrated, and the following Equation (9) obtained:

$\int_{0}^{\alpha} \frac{\mathrm{d} \alpha}{\alpha^{m}(1-\alpha)^{n}[-\ln (1-\alpha)]^{p}}=\frac{A}{q} \int_{0}^{T} \exp \left[-\frac{E}{R T}\right] \mathrm{d} T$

The left-hand side of the equation represents $g(\alpha)$ obtained by integration of conversion function of $f(\alpha)$, which explicitly represents the mechanism. Table 1 presents mechanisms as algebraic expressions effective in solid-state reactions ${ }^{39,42,43}$.

In Equation (9), the integral on the right-hand side has no precise analytical solution; therefore, the Coats and Redfern calculation procedure ${ }^{44}$ was used for prediction of activation energy by means of an approximate expression.

Equation (4) considers the maximum reaction rate and leads to Equation (10):

$$
-\frac{1}{\frac{\mathrm{d} f(\alpha)}{\mathrm{d} \alpha}}=-\frac{1}{f^{\prime}\left(\alpha_{\max }\right)}=\frac{A}{q} \frac{R T^{2}}{E} \exp \left[\frac{E}{R T_{\max }}\right]
$$

The variables at the maximum reaction rate are denoted by subscript 'max'. Moreover, when Equation (9) is combined with Equation (10), the resulting Equation (11) is as given below.

$$
g\left(\alpha_{\max }\right) f^{\prime}\left(\alpha_{\max }\right)=-h\left[\frac{E}{R T_{\max }}\right]
$$

Equation (10) designates that $\alpha_{\max }$ value is dependent on $E / R T_{\max }$ for a fixed kinetic model. In or-

Table 1 - Comparing degradation temperatures

\begin{tabular}{cccc|c|c}
\hline Sample & $T_{\text {onset }}\left({ }^{\circ} \mathrm{C}\right)$ & $T_{0.5}\left({ }^{\circ} \mathrm{C}\right)$ & $T_{\max }$ & Peak rate \\
\hline PC & 433 & 511 & 517 & $1.36 \%{ }^{\circ} \mathrm{C}^{-1}$ \\
$3 \%$ PCNC & 429 & 489 & 485 & $1.32 \%{ }^{\circ} \mathrm{C}^{-1}$ \\
\hline
\end{tabular}


der to evaluate the limits of $\alpha_{\text {max }}$ for different kinetic models, Equation (10) can be applied and used to determine the magnitude of $\alpha_{\max }$ that can be further used to classify the kinetic models.

For the present study, the non-isothermal modelistic method Coats and Redfern ${ }^{44}$ was employed. The kinetic parameters are determined in the range of $0.1-0.6(\alpha)$ using the data set as obtained from TG and DTG curves. Using a modified Coats and Redfern Equation (12) as given below, the kinetic parameters can be determined.

$$
\ln \frac{g(\alpha)}{T^{2}}=\ln \frac{A R}{q E}-\frac{E}{R T}
$$

where, $g(\alpha)$ is a function, an integral of $f(\alpha)$, which is influenced by the kinetic model of the occurring reaction. From Equation (12), a plot of $\ln \left[g(\alpha) / T^{2}\right]$ against $1 / T$ results in a straight line, and its slope and intercept correspond to activation energy $E$ and pre-exponential factor $A$, respectively. The mathematical model and conversion mechanism will decide the algebraic expression for the functions $g(\alpha)^{39,42}$. The true $g(\alpha)$ can be obtained if one attains a maximum correlation coefficient for its linear dependency.

The temperature integral in Equation (9) has been solved by different authors ${ }^{45,46}$ and they suggested different solutions. For example, Madhysudanan-Krishnan-Ninan ${ }^{45}$ suggested Equation (13).

$$
\begin{aligned}
\ln \left[\frac{g(\alpha)}{T^{1.92503}}\right]= & \ln \left[\frac{A R}{q E}+3.772050-1.921503 \ln E\right]- \\
& -0.120394 \frac{E}{T}
\end{aligned}
$$

Equations 12 and 13 demonstrate that the calculated values of the activation energy $E$ and pre-exponential factor $A$ using same $g(\alpha)$ are different to a certain extent.

It has been established that, for solid phase reactions, the values of pre-exponential factor $A$ are not expected to be within a definite range ${ }^{37,39}$. It is given in literature that empirical first-order pre-exponential factors may vary from $10^{4}$ to $10^{18} \mathrm{~s}^{-1}$. Lower values of $A$ point towards a surface reaction. If the reactions are independent of surface area, the low values indicate a tight complex. Higher values of $A$ factors prove that the complex is loose. It is highly desirable to obtain an indication of molecularity from the magnitude of the pre-exponential, since in many cases, the concentrations in the solid cannot be controlled ${ }^{47}$.

Eyring Equation $^{36-39}$, is given by Equation (14) and it is the theory of transition state, activated complex.

$$
A=\frac{e \chi k_{B} T_{p}}{h} \exp \left[\frac{\Delta S^{*}}{R}\right]
$$

where, the Neper number $e=2.7183$, transmission factor $\chi=1$ for monomolecular reactions, Planck constant $h$, Boltzmann constant $k_{B}$, and the peak temperature $T$ obtained from the DTG curve. $\Delta S^{*}$ representing the change in entropy is given by Equations (15) and (16) $)^{37,39}$,

$$
\Delta S^{*}=R \ln \frac{A h}{e \chi k_{B} T_{p}}
$$

Since

$$
\Delta H^{*}=E-R T_{p}
$$

The well-established thermodynamic Equation (17) can be used to calculate the changes in enthalpy $\Delta H^{*}$ and Gibbs free energy $\Delta G^{*}$ for the formation of activated complex from the reagent.

$$
\Delta G^{*}=\Delta H^{*}-T_{p} \Delta S^{*}
$$

\section{Artificial Neural Network}

An artificial neural network, which imitates a nervous system, is capable of recognizing patterns similar to the brain, and consists of neurons or nodes as the processing units. The interconnected neurons are arranged in layers, such as input, hidden, and output layer. Based on the input variables, neurons in the input layers are finalized and the number of responses decide the neurons in the output layer. Each layer comprises of a weight, bias and output vector. When the data is transferred as a signal from one neuron to the next neuron, the output is obtained after the signal from the previous neuron is multiplied by the weight, adjusted by the activation function, and diverged by the bias. The learning algorithm regulates the weights of the processing neurons by minimizing the possible errors in the network output. The hidden layer acts like a brain as input passes through hidden layer and processes it as output. Training of a system involves adjustment of weight and bias to achieve the lowest mean squared error (mse), which is nothing but the performance. The major stages involved in designing the ANN model after processing of the data set is building the network where the transfer functions are decided for the hidden and output layers. This is followed by training, which uses $70 \%$ of the data, while the remaining $30 \%$ are divided and used in validation and testing. The validation step checks for the performance, and when it finds that no further improvement of the performance is possible, it stops the training, whereas the testing is carried out independently. The normalization of the dataset utilizes Equation (18): 


$$
y=\left(\frac{x_{i}-x_{\min }}{x_{\max }-x_{\min }}\right)
$$

where, the normalized value of $x_{i}$ is $y$, and the maximum and minimum values of $x_{i}$ are denoted by $x_{\max }$ and $x_{\min }$, respectively.

The output neuron for a system is obtained by Equation (19)

$$
t=a\left(\sum_{i=1}^{n} w_{i} x_{i}-b\right)
$$

where, $x_{i}$ is the input signal, $i=1,2, \ldots, n$, $\mathrm{i}^{\text {th }}$ weight is $w_{i}$, bias is $b$, and the transfer function $a$.

Here, the network consists of three layers with feed forward mode through tangent sigmoid as the transfer function (tansig) for the hidden layer, and a linear transfer function (purelin) for the layer as output. The linear activation function is given by Equation 20. The tan sigmoid function is denoted by Equation 21 .

$$
\begin{gathered}
f(x)=x \\
\operatorname{tansig}(x)=\frac{2}{1+e^{-2 x}}-1
\end{gathered}
$$

The mean squared error (mse) determines the performance, and coefficient of determination $\left(R^{2}\right)$ is an additional support, as given by Equation 22 and 23 .

$$
\begin{aligned}
& M S E=\sqrt{\sum_{i=1}^{n} \frac{\left(y_{p r d, i}-y_{\exp , i}\right)}{n}} \\
& R^{2}=1-\frac{\sum_{i=1}^{n}\left(y_{p r d, i}-y_{\exp , i}\right)^{2}}{\sum_{i=1}^{n}\left(y_{p r d, i}-y_{m}\right)}
\end{aligned}
$$

where, $y_{p r d, i}$ is the data predicted, the experimental data corresponding to predicted is $y_{\text {exp, } i}$, the number of data obtained experimentally is $n$, and its average is $y_{m}$.

A sensitivity analysis is performed for assessing the comparative significance of each input variable on the output, and is given by Garson as inEquation (24)

$$
I_{j}=\frac{\sum_{m=1}^{m=N h}\left(\left(\left|W_{j m}^{i h}\right| / \sum_{K=1}^{N i}\left|W_{K m}^{i h}\right|\right) \cdot\left|W_{m n}^{h o}\right|\right)}{\sum_{k=1}^{k=N i}\left\{\sum_{m=1}^{m=N h}\left(\left|W_{k m}^{i h} / \sum_{K=1}^{N i}\right| W_{k m}^{i h}|\cdot| W_{m n}^{h o} \mid\right)\right\}}
$$

where, $I j$ is the relative significance of the $j t h$ input variable on the output variable. The number of in- put and hidden neurons is denoted as $N i$ and $N h$, respectively. The connection weight is denoted by $W$. The input, hidden, and output layers are represented by the superscripts $I, h$, and $o$, respectively. The input, hidden, and output neurons are referred to as subscripts $k, m$, and $n$, respectively.

\section{Results and discussion}

\section{TGA}

The thermogravimetric curves of pure polycarbonate (PC) and reinforced PC filled with $3 \%$ $\mathrm{CaCO}_{3}$ (PCC) are shown in Fig. 1. The Table 1 indicates $5 \%$ and $50 \%$ degradation along with the mass residue. Usually, polymer degradation obeys the sigmoidal or deceleration functions ${ }^{42}$. Pure PC starts degrading at $433^{\circ} \mathrm{C}$, whereas, $\mathrm{PCC}$ degradation starts at a temperature lower than that of pure PC. A shift towards lower temperature indicates that the presence of $3 \% \mathrm{CaCO}_{3}$ nanofillers lead to a decrease in the thermal stability of PC. This is due to the manifestation of organic modifier on the fillers leading to catalysis of the degradation process ${ }^{47}$. In the first stage of degradation, after evaporation of free and bound moisture, the complete loss of carbonate and partial degradation of isopropylidene group takes place. This is followed by the final degradation of aromatic rings ${ }^{48}$. Figs. $2 \mathrm{a}$ and $2 \mathrm{~b}$ represent the curves obtained from TG and DTG for the degradation of PCC at different heating rates. The four different heating rates chosen for the study were $5,10,15,20{ }^{\circ} \mathrm{C} \mathrm{min}^{-1}$. The Figs. $2 \mathrm{a}$ and $2 \mathrm{~b}$ indicate the effect of heating rates on the process of degradation. Initially, the water removal region for all the heating rates is the same. It is observed that, with increasing heating rate, the TG curve and the maximum peak temperature $\left(T_{\max }\right)$ shifts to higher temperature. It is well known that polymer absorbs

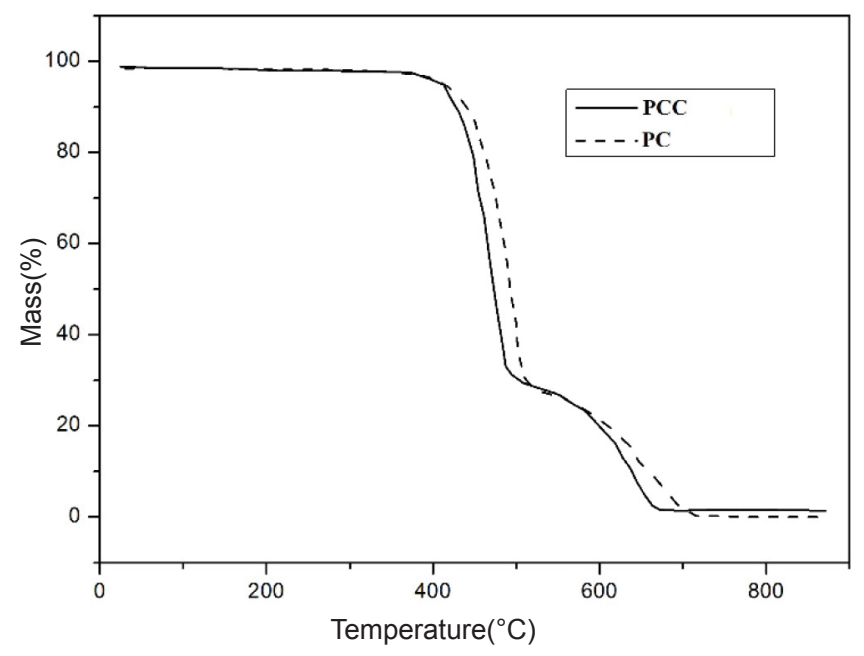

Fig. 1 - TGA curves of pure PC and PCC 
A- $5{ }^{\circ} \mathrm{C} \mathrm{min}^{-1}, \mathrm{~B}-10{ }^{\circ} \mathrm{C} \mathrm{min}^{-1}, 15-5^{\circ} \mathrm{C} \mathrm{min}^{-1}, \mathrm{D}-20^{\circ} \mathrm{C} \mathrm{min}^{-1}$

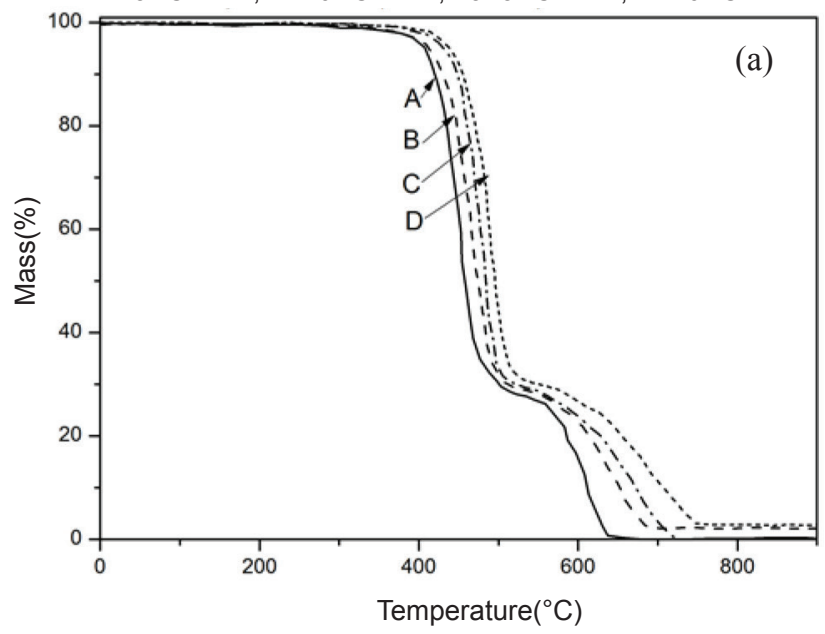

A- $5{ }^{\circ} \mathrm{C} \min ^{-1}$, B- $10{ }^{\circ} \mathrm{C} \min ^{-1}, 15-5{ }^{\circ} \mathrm{C} \min ^{-1}$, D- $20^{\circ} \mathrm{C} \min ^{-1}$

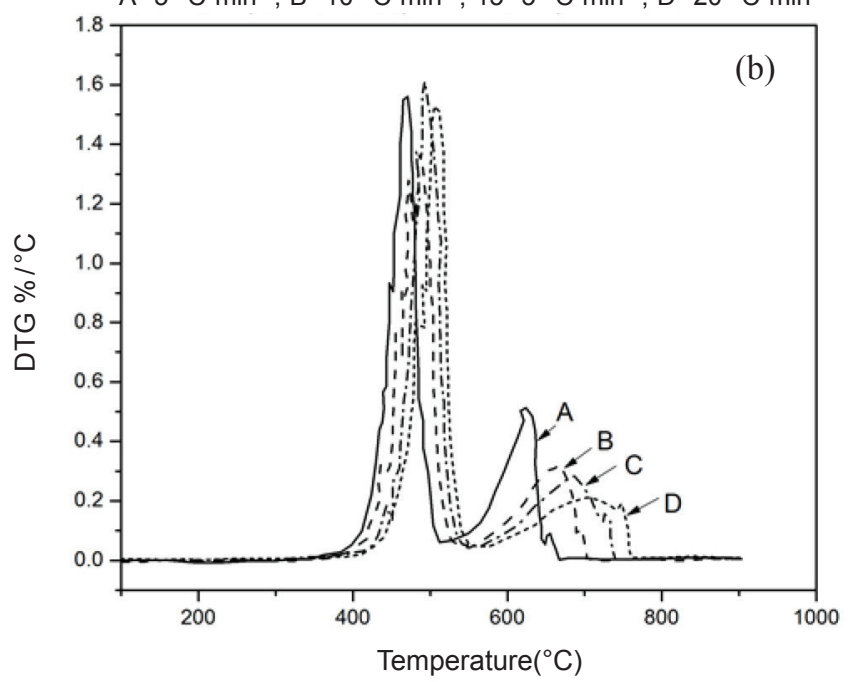

Fig. 2 - (a) TGA curves of pure PC and PCC at different heating rates, (b) DTG curves representing the peak temperatures of pure PC and PCC at different heating rates

energy before decomposing. At a higher heating rate, the decomposition is detected at higher temperatures $^{49}$. If heating rates are lower, a larger amount of instantaneous thermal energy needs to be supplied to the system, and it might take longer for the purge gas to reach equilibrium with the prevailing temperature conditions of the furnace. Since a higher heating rate enables the reaction to take place in a shorter time, accordingly, the temperature necessary to degrade the sample is also higher, resulting in the shift of the DTG curve to higher temperature ${ }^{50}$.

\section{Kinetic studies}

\section{Model-free kinetics}

Initially, the Kissinger model-free method, known as the peak temperature method, was used to obtain the values of activation energy, $E$. The val-
Table 2 - Kinetic data for degradation of PC and $3 \%$ PCNC by Kissinger method

\begin{tabular}{c|c|c|c|c|c|c}
\hline \multirow{2}{*}{ Atmosphere } & \multirow{3}{*}{ Samples } & \multicolumn{4}{|c|}{$T_{\mathrm{m}}(\mathrm{k})$} & \multirow{2}{*}{\begin{tabular}{c}
$E$ \\
\cline { 3 - 6 }
\end{tabular}} \\
& & $\begin{array}{c}5 \\
{ }^{\circ} \mathrm{C} \mathrm{min}^{-1}\end{array}$ & $\begin{array}{c}10 \\
{ }^{\circ} \mathrm{C} \mathrm{min}^{-1}\end{array}$ & $\begin{array}{c}15 \\
{ }^{\circ} \mathrm{C} \mathrm{min}^{-1}\end{array}$ & $\begin{array}{c}20 \\
{ }^{\circ} \mathrm{C} \mathrm{min}^{-1}\end{array}$ & $\left(\mathrm{~kJ} \mathrm{~mol}^{-1}\right)$ \\
\hline \multirow{2}{*}{ Nitrogen } & PC & 496 & 516 & 530 & 538 & 156 \\
& PCNC & 469 & 486 & 490 & 502 & 194 \\
\hline
\end{tabular}

ues, as given in Table 2, were used as a reference for selecting the best model and deciding the mechanism of reaction.

\section{Modelistic kinetics}

By means of the Coats and Redfern method ${ }^{44}$, substitution of $g(\alpha)$ functions into Equation (13) gave a linear equation. The left side of the equation was plotted against $1 / T$ to compute the linear regression coefficient $\left(R^{2}\right)$ for the thermal degradation of the samples studied. The single heating rate plots on the left-hand side, $\ln \left[g(\alpha) / T^{2}\right]$ against $1 / T$, were computed for the thermal degradation as per Equation 12. In the case of the modelistic methods, the coefficient of linear regression $\left(R^{2}\right)$ generally plays an important role in deciding a suitable reaction mechanism. It is also suggested that comparing the activation energy obtained from modelistic methods with the activation energy obtained from model-free methods help in deciding the best mechanism. Table 3 lists the different mechanisms $g(\alpha)$ in modelistic methods. Table 4 designates the values of kinetic parameters obtained for various mechanisms along with coefficient of regression for comparison with the model-free method results. The kinetic parameters were compared with model-free method and the mechanism was thus finalized. The same study was carried out with another non-isothermal procedure, as described by Madhysudanan-Krishnan-Ninan ${ }^{45}$. The kinetic mechanism of PCC follows chemical reaction mechanisms. Using the two non-isothermal methods, the values calculated for $E$ and $A$ are almost the same, thus, an average of these values was considered for further evaluation.

At $T=T_{p}$, the values of $\Delta S^{*}, \Delta H^{*}$, and $\Delta G^{*}$ were obtained using average values of $E$ and $A$, as given in Table 5. $T=T_{p}$ characterizes the highest process rate, and consequently, is a significant parameter. The change in Gibbs free energy, $\Delta G^{*}$, reveals the total energy increase in the system when reagents approach and the activated complex are formed. In turn, $\Delta G^{*}$ is influenced by the enthalpy changes $\Delta H^{*}$ and changes in entropy $\Delta S^{*}$. The $\Delta H^{*}$, which is a thermodynamic property, gives an idea of the differences in energy between the activated complex and reagents. The lower levels of energy indicate that the potential barrier is low, leading to 
Table 3 -Algebraic expressions of the functions $f(\alpha)$ and integral form as $g(\alpha)$ and its corresponding mechanism

\begin{tabular}{|c|c|c|c|c|c|}
\hline No. & Kinetic model & Symbol & $g(\alpha)$ & $f(\alpha)$ & Rate-determining mechanism \\
\hline \multicolumn{6}{|c|}{ n-Order reactions } \\
\hline 1 & First order & $F_{1}$ & $-\ln (1-\alpha)$ & $(1-\alpha)$ & Chemical reaction \\
\hline 2 & Second-order & $F_{2}$ & $(1-\alpha)^{-1}-1$ & $(1-\alpha)^{2}$ & Chemical reaction \\
\hline 3 & Third-order & $F_{3}$ & $(1-\alpha)^{-2}-1$ & $1 / 2(1-\alpha)^{3}$ & Chemical reaction \\
\hline 4 & One-third-order & $F_{1 / 3}$ & $1-(1-\alpha)^{2 / 3}$ & $3 / 2(1-\alpha)^{1 / 3}$ & Chemical reaction \\
\hline 5 & Three-quarters-order & $F_{3 / 4}$ & $1-(1-\alpha)^{1 / 4}$ & $4(1-\alpha)^{3 / 4}$ & Chemical reaction \\
\hline 6 & One-and-a-half-order & $F_{3 / 2}$ & $(1-\alpha)^{1 / 2-1}$ & $2(1-\alpha)^{3 / 2}$ & Chemical reaction \\
\hline \multicolumn{6}{|c|}{ Diffusion } \\
\hline 7 & 1-D diffusion & $D_{1}$ & $\alpha^{2}$ & $1 / 2 \alpha$ & One-dimensional diffusion \\
\hline 8 & 2-D diffusion & $D_{2}$ & $\alpha+(1-\alpha) \ln (1-\alpha)$ & {$[-\ln (1-\alpha)]^{-1}$} & Two-dimensional diffusion \\
\hline 9 & 3-D diffusion & $D_{3}$ & {$\left[1-(1-\alpha)^{1 / 3}\right]^{2}$} & $(3 / 2)(1-\alpha)^{2 / 3}\left[1-(1-\alpha)^{1 / 3}\right]^{-1}$ & Three-dimensional diffusion \\
\hline \multicolumn{6}{|c|}{ Phase-boundary reactions } \\
\hline 10 & Contracting area & $R_{2}$ & $1-(1-\alpha)^{1 / 2}$ & $2(1-\alpha)^{1 / 2}$ & Contracting cylinder \\
\hline 11 & Contracting area & $R_{3}$ & $1-(1-\alpha)^{1 / 3}$ & $3(1-\alpha)^{2 / 3}$ & Contracting sphere \\
\hline \multicolumn{6}{|c|}{ Nucleation and nuclei growth } \\
\hline 12 & Avrami-Erofeev & $A_{2}$ & {$[-\ln (1-\alpha)]^{1 / 2}$} & $2(1-\alpha)[-\ln (1-\alpha)]^{1 / 2}$ & Random nucleation, $\mathrm{n}=2$ \\
\hline 13 & Avrami-Erofeev & $A_{3}$ & {$[-\ln (1-\alpha)]^{1 / 3}$} & $3(1-\alpha)[-\ln (1-\alpha)]^{2 / 3}$ & Random nucleation, $\mathrm{n}=3$ \\
\hline \multicolumn{6}{|c|}{ Acceleratory rate equations } \\
\hline 14 & Mampel Power law & $P_{3 / 2}$ & $\alpha^{3 / 2}$ & $(2 / 3) \alpha^{-1 / 2}$ & Nucleation \\
\hline 15 & Mampel Power law & $P_{1 / 2}$ & $\alpha^{1 / 2}$ & $2 \alpha^{-1 / 2}$ & Nucleation \\
\hline 16 & Mampel Power law & $P_{1 / 3}$ & $\alpha^{1 / 3}$ & $3 \alpha^{2 / 3}$ & Nucleation \\
\hline 17 & Mampel Power law & $P_{1 / 4}$ & $\alpha^{1 / 4}$ & $4 \alpha^{3 / 4}$ & Nucleation \\
\hline
\end{tabular}

Table 4 -Results obtained for various mechanisms using Coats-Redfern method of calculation

\begin{tabular}{|c|c|c|c|c|c|c|}
\hline Model & \multicolumn{3}{|c|}{ Pure PC } & \multicolumn{3}{|c|}{$3 \% \mathrm{PCNC}$} \\
\hline Model-free method & \multicolumn{3}{|c|}{$E a=156$} & \multicolumn{3}{|c|}{$E a=194$} \\
\hline \multicolumn{7}{|c|}{ Chemical process or mechanism-non-invoking equations } \\
\hline & $E$ & $\ln A$ & $R^{2}$ & $E$ & $\ln A$ & $R^{2}$ \\
\hline 0 -order & 128.4762 & 10.7127 & 0.9988 & 153.3434 & 15.45932 & 0.9853 \\
\hline 1-order & 156.5111 & 15.53077 & 0.9988 & 187.2479 & 21.33708 & 0.9968 \\
\hline 2-order & 189.2765 & 21.10885 & 0.9916 & 227.0055 & 28.17562 & 0.9999 \\
\hline $3 / 2$ & 172.3077 & 17.53193 & 0.9959 & 206.3951 & 23.94344 & 0.9992 \\
\hline 3 -order & 226.6147 & 28.1109 & 0.9801 & 272.4248 & 36.63101 & 0.9971 \\
\hline \multicolumn{7}{|c|}{ Acceleratory rate equations } \\
\hline $\mathrm{P} 3 / 2$ & 199.0455 & 21.62118 & 0.9989 & 236.2091 & 28.62536 & 0.9861 \\
\hline \multicolumn{7}{|c|}{ Sigmoidal rate equations or random nucleation and subsequent growth } \\
\hline $\mathrm{N}=1.5$ & 100.6909 & 6.6542 & 0.9987 & 118.7401 & 10.60338 & 0.9965 \\
\hline \multicolumn{7}{|c|}{ Deceleratory rate equations } \\
\hline \multicolumn{7}{|c|}{ a. Phase boundary reactions (power law) } \\
\hline $\mathrm{R} 1, \mathrm{~F} 0, \mathrm{P} 1$ & 128.4762 & 10.7127 & 0.9988 & 153.3434 & 15.45932 & 0.9853 \\
\hline $\mathrm{R} 2, \mathrm{~F} 1 / 2$ & 141.9034 & 12.33389 & 0.9999 & 169.564 & 17.58487 & 0.9922 \\
\hline $\mathrm{R} 3, \mathrm{~F} 2 / 3$ & 146.7421 & 12.74822 & 0.9997 & 175.309 & 18.17319 & 0.9939 \\
\hline \multicolumn{7}{|c|}{ b. Based on the diffusion mechanism } \\
\hline D1 & 269.6064 & 32.39561 & 0.999 & 319.0664 & 49.9099 & 0.9865 \\
\hline D6 & 248.7133 & 26.61595 & 0.9975 & 294.0994 & 35.13956 & 0.982 \\
\hline
\end{tabular}


Table 5 -Kinetic parameters obtained for non-isothermal degradation of pure $P C$ and $P C N C$

\begin{tabular}{ccc}
\hline \multirow{2}{*}{ Parameters } & \multicolumn{2}{|c}{ Sample } \\
\cline { 2 - 3 } & Pure PC & $3 \%$ PCNC \\
\hline Coats-Redfern \\
\hline$R^{2}$ & $\begin{array}{c}\text { Chemical process } \\
\text { (1 }{ }^{\text {st } \text { order })}\end{array}$ & $\begin{array}{c}\text { Chemical process } \\
(3 / 2 \text { order })\end{array}$ \\
$E\left(\mathrm{~kJ} \mathrm{~mol}^{-1}\right)$ & 0.9988 & 0.9992 \\
$A\left(\mathrm{~min}^{-1}\right)$ & 156 & 206 \\
\multicolumn{1}{c}{$\mathrm{Madhysudanan}-\mathrm{Krishnan}-\mathrm{Ninan}^{-1}$} & $2.6 \cdot 10^{10}$ \\
\hline$E\left(\mathrm{~kJ} \mathrm{~mol}^{-1}\right)$ & 156 & 207 \\
$A\left(\mathrm{~min}^{-1}\right)$ & $3.2 \cdot 10^{6}$ & $2.9 \cdot 10^{10}$ \\
\hline & Average values \\
\hline$E\left(\mathrm{~kJ} \mathrm{~mol}^{-1}\right)$ & 156 & 206 \\
$A\left(\mathrm{~min}^{-1}\right)$ & $3.2 \cdot 10^{6}$ & $2.9 \cdot 10^{10}$ \\
$-\Delta S^{*}\left(\mathrm{~J} \mathrm{~mol}^{-1} \mathrm{~K}^{-1}\right)$ & 137 & 60.7 \\
$\Delta H^{*}\left(\mathrm{~kJ} \mathrm{~mol}^{-1}\right)$ & 149 & 200 \\
$\Delta G^{*}\left(\mathrm{~kJ} \mathrm{~mol}^{-1}\right)$ & 257 & 246 \\
\hline
\end{tabular}

the formation of activated complex. The $\Delta S^{*}$ gives an indication of the system's closeness to achieving thermodynamic equilibrium. A high $\Delta S^{*}$ value specifies high reactivity, leading to the system's fast response to producing activated complex. The results showed that, with the increase in $E$ values, the values of $A$ increased. The observed result suggests the existence of isokinetic compensation effect. This means that the most likely equation established can describe the mechanism of thermal degradation of the samples. Also, if values of $E$ increase with the $\Delta S^{*}$ values, it indicates that higher $E$ values correspond to lower entropy. Thus, we can say that a small decrease in entropy is expected during the reshuffling of the composite structure when activated complex is formed ${ }^{47,51}$.

\section{Artificial neural network (ANN)}

We have used MATLAB based NN toolbox, version R2012a $\mathrm{a}^{52}$ for developing the model. This tool supports supervised learning with feedforward, backpropagation, radial basis, and dynamic networks ${ }^{53}$. The data generated by the non-isothermal kinetic study of polycarbonate composites was used here as the input and output for generating the model. The input variables were degree of conversion $(\alpha)$, temperature in $K$ corresponding to $\alpha$, and time in minutes based on heating rates $(5,10,15$ and 20 $\left.{ }^{\circ} \mathrm{C} \mathrm{min}^{-1}\right)$. The data makes use of four different heating rates and conversions from 10 to $60 \%$ with a difference of $5 \%$. Here, we attempted to predict the outputs independently for each kinetic parameter. The output parameters were the kinetic triplets: activation energy $(E)$, pre-exponential factor $(A)$, and mechanism $(n)$. The dataset used consisted of 43 samples as described in supplementary Table S1.

The feedforward backpropagation method was used, where signal flows only from input to output. The artificial neural network architecture consisted of elementary layers as input, hidden, and output layers. Neural networks can learn and adjust the weights and bias to achieve the desired outputs related to the set of inputs by minimizing the error between the predicted and actual experimental output. The optimization technique used here was Levenberg-Marquardt. The network was trained using different topology, and the one that provided least mean squared error (mse), with hidden layer having sufficient number of neurons, was selected because it could successfully approximate any nonlinear functions.

The activation or transfer functions benefit learning of the nonlinear relationships amongst the input and output variables. Here, the hidden layer was assigned sigmoid activation function (hyperbolic tangent) and the output layer was purlinear ${ }^{52}$.

The performance evaluation of the model in predicting properties was evaluated in terms of mse. Least mse indicate the best fit, and the ideal value is zero or less than zero indicating no error.

Regression coefficients $(R)$ were used in addition to the mse to keep a check on the performance. They can measure the correlation between experimental and predicted values. The ideal value is always 1 or close to 1 .

The network for the three outputs was designed independently, and the complete data could be divided into training $(70 \%)$, validation $(15 \%)$, testing $(15 \%)$. To decide the optimum number of hidden layers, the network was trained and checked for the mse as well as $R$. A single hidden layer was chosen, since in most cases, excellent results have been obtained with single hidden layer ${ }^{54}$. It is expected that the efficiency of the model network could increase with the number of neurons in the hidden layer, but may lead to overfitting ${ }^{53}$.

The various parameter settings for the training are shown in Table 6.

The model network topology selected for $E$ as output was 3-10-1, indicating that the hidden layer consisted of 10 neurons. A network of 3-8-1 was successfully applied to determine $\ln A$, and 3-5-1 for determining the mechanism $(n)$.

The performance curve for training with $m s e$ as the performance criteria in the case of $E$ prediction is shown in Fig. 3a. Best validation performance occurs at 8 epochs. The training stops when the validation error increases, which occurs at 12 epochs. 
Table 6 - Parameter settings for training ANN model

\begin{tabular}{|c|c|c|c|}
\hline \multirow{2}{*}{ Neural network parameters } & \multicolumn{3}{|c|}{ Selected values } \\
\hline & $E$ & $\ln A$ & $\mathrm{n}$ \\
\hline 1. Input layer neurons & 3 & 3 & 3 \\
\hline 2. Number of hidden layers & 1 & 1 & 1 \\
\hline 3. Number of neurons in the hidden layers & 10 & 8 & 5 \\
\hline 4. Number of neurons in the output layer & 1 & 1 & 1 \\
\hline 5. Activation function of hidden layers & Tansig & Tansig & Tansig \\
\hline 6. Activation function of output layers & Purelin & Purelin & Purelin \\
\hline 7. Training algorithm & Levenberg-Marquardt & Levenberg-Marquardt & Levenberg-Marquardt \\
\hline 8. Number of epochs & 1000 & 1000 & 1000 \\
\hline
\end{tabular}

(a)

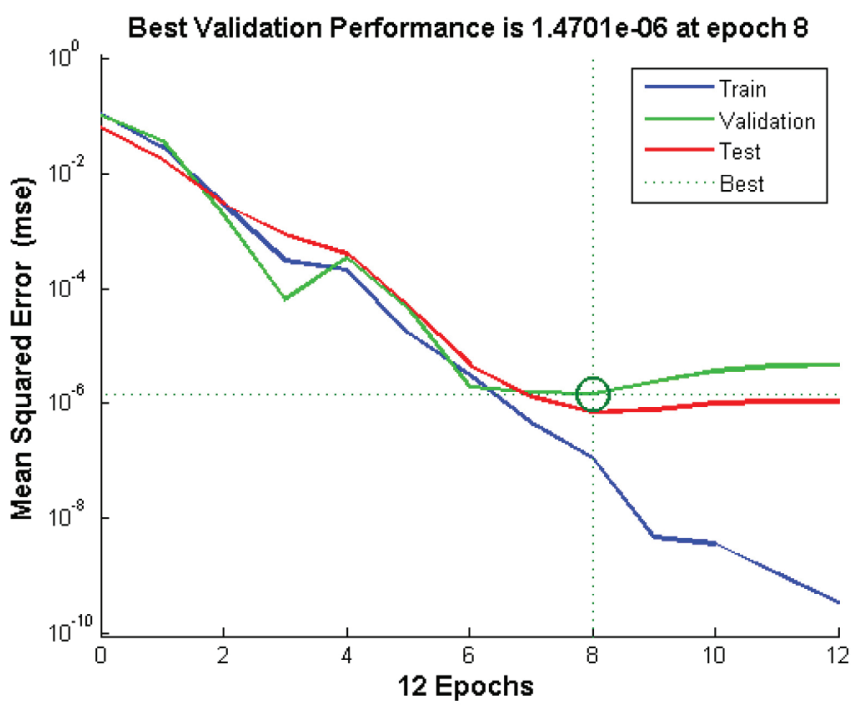

(b)

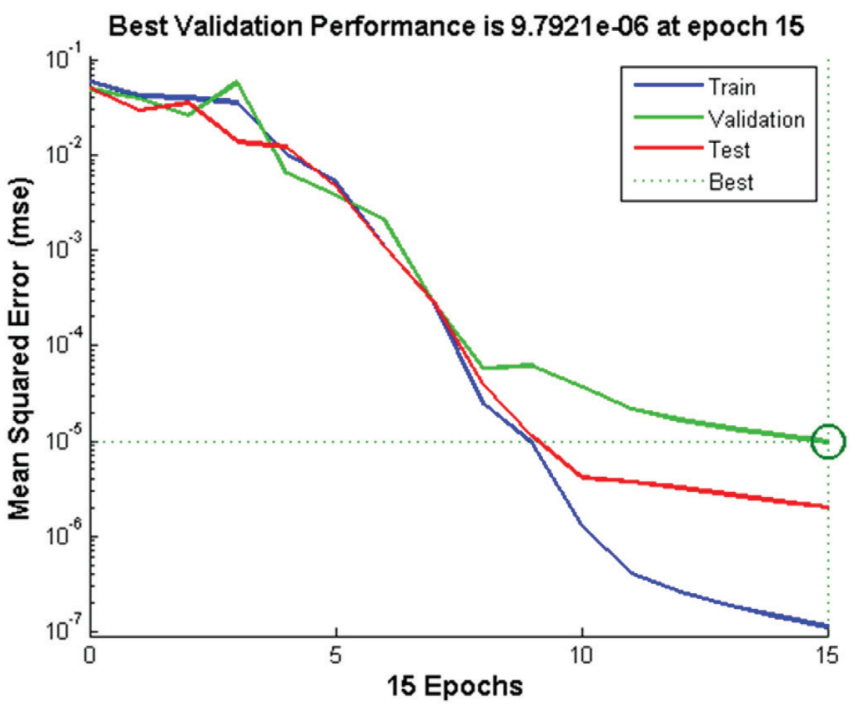

(c)

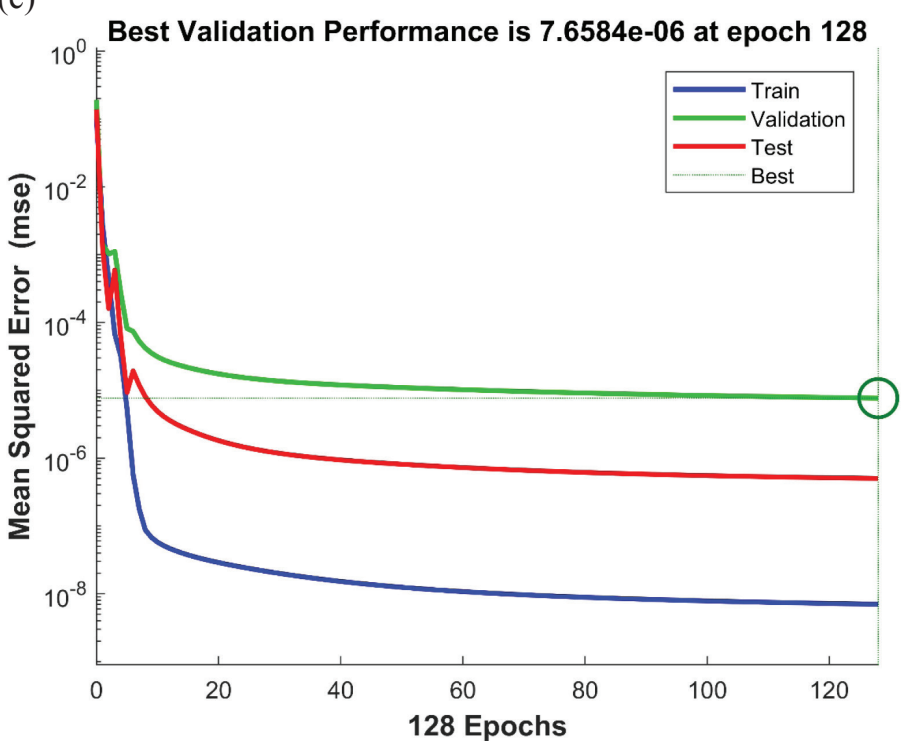

Fig. 3 - (a) Performance curve for the case of activation energy (E), (b) Performance curve for the case of pre-exponential factor (InA), (c) Performance curve for the case of mechanism (n) 

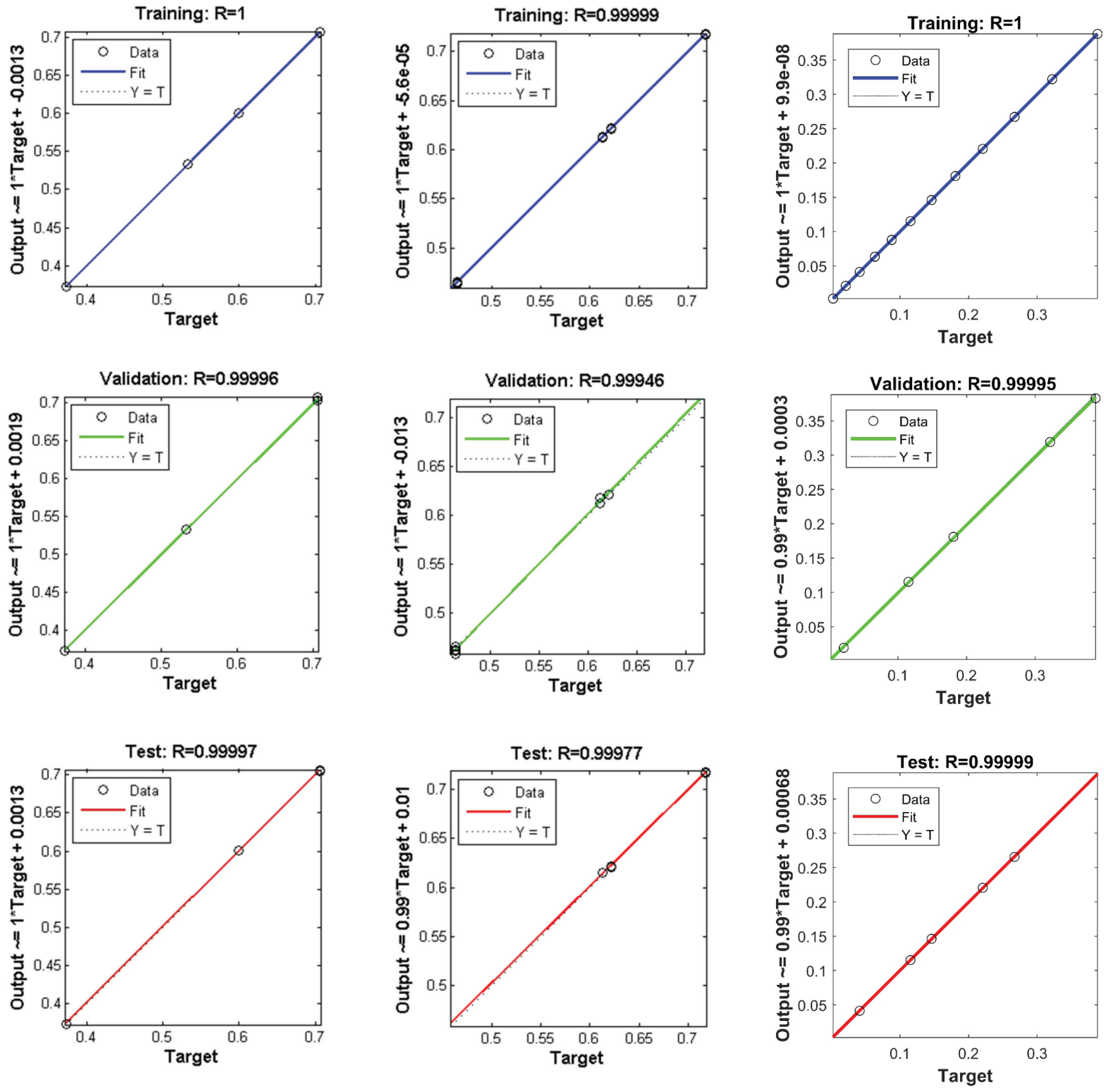

All: $\mathbf{R}=0.99999$

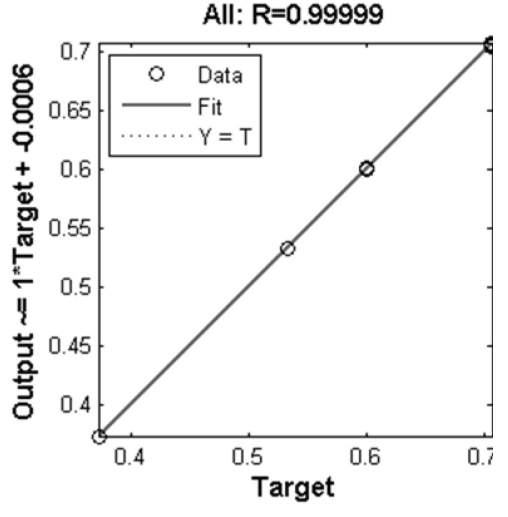

(a)

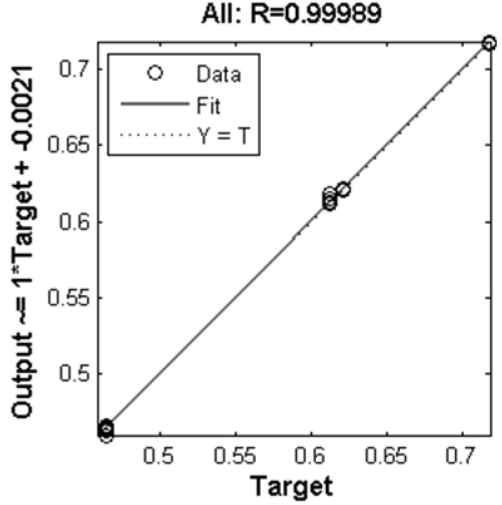

(b)

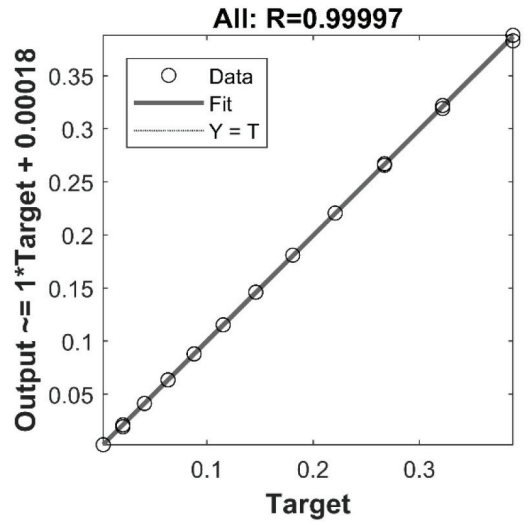

(c)

Fig. 4 - (a) Regression plot for training, validation, and testing of activation energy (E), (b) Regression plot for training, validation, and testing of pre-exponential factor (InA), (c) Regression plot for training, validation, and testing of reaction mechanism (n) 

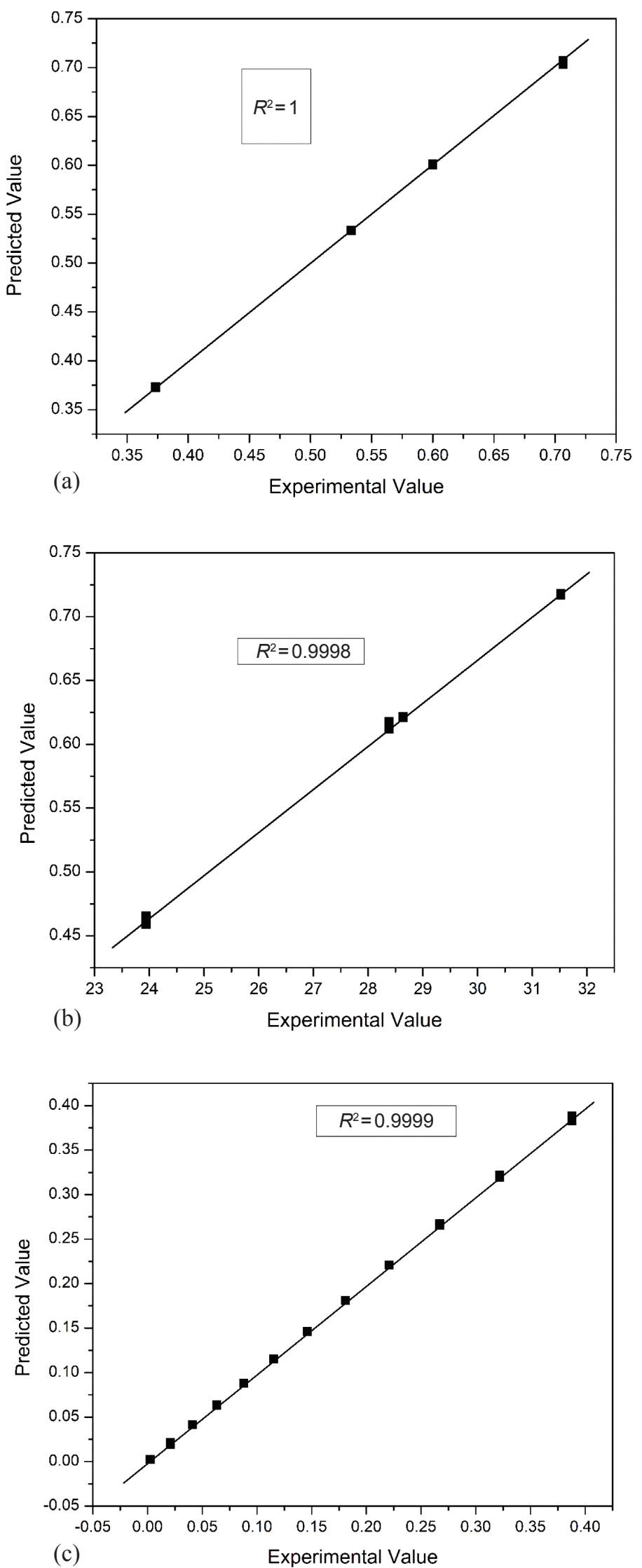

Fig. 5 - (a) Comparison of the experimental $E$ values with the predicted $E$ values (ANN), (b) Comparison of the experimental $\ln A$ values with the predicted $\ln A$ values (ANN), (c) Comparison of the experimental $n$ value with the predicted $n$ values (ANN)
Test and validation error follows the same trend pointing to best results. Similarly, performance curves for $\ln A$ and mechanism ( $n)$ are shown in Fig. $3 \mathrm{~b}$ and $3 \mathrm{c}$, respectively. Best validation performance occurs at 15 for $\ln A$ and 128 for $n$.

The regression plot shows a linear relation between the predicted output and the target, as represented by regression coefficients, $R$, close to 1 , shown in Figs. $4 \mathrm{a}, 4 \mathrm{~b}$, and $4 \mathrm{c}$ for training, validation, and testing of the kinetic parameters. A correlation coefficient close to 1 was observed for the prediction of all the three kinetic factors. The ANN output predicted from the network was compared with the experimental values for $E, \ln A$, and $n$, with a coefficient of correlation close to 1 , as shown in Figs. 5a, 5b, and 5c, respectively. The network was tested with some new points excluding the dataset, and the coefficient of correlation achieved was close to 1 , confirming the generalized capability of the network to predict kinetic parameters. Figs. 6a, $6 \mathrm{~b}$, and $6 \mathrm{c}$ represent the graphs for the test samples of $E, \ln A$, and $n$, respectively.

The relative significance of each input variable on the output was obtained by sensitivity analysis using Garson's equation as explained previously. Table 7 represents the relative influence $(\%)$ of input variables on output $E, \ln A$, and $n$, respectively. Evidently, time as input variable, had the most influence on all the kinetic parameters. Time is based on heating rates; thus, heating rates are the most important parameters for the evaluation of kinetics. The second most important parameter influencing the kinetic parameters was confirmed to be temperature. The importance of variables was established to be in the order of

$$
\text { Time }>\text { Temperature }>\text { Conversion. }
$$

\section{Conclusions}

The results established based on two different non-isothermal methods (Coats-Redfern and Madhysudanan-Krishnan-Ninan) were quite comparable, implying that an average of the two could be taken. The kinetic parameters $\left(E, A, \Delta S^{*}, \Delta H^{*}\right.$, and $\left.\Delta G^{*}\right)$ were calculated for all the samples. It can be concluded that the system is non-spontaneous. Modelistic methods and model-free methods provide almost the same values of activation energy.

Table 7 -Relative importance of input variables on the output kinetic parameters

\begin{tabular}{c|c|c|c}
\hline $\begin{array}{c}\text { Kinetic } \\
\text { parameters }\end{array}$ & Time (min) & $\begin{array}{c}\text { Temperature } \\
(\mathrm{K})\end{array}$ & $\begin{array}{c}\text { Conversion } \\
(\%)\end{array}$ \\
\hline$E$ & $42.5 \%$ & $40.51 \%$ & $16.98 \%$ \\
$\ln A$ & $41.57 \%$ & $35.5 \%$ & $22.88 \%$ \\
$n$ & $46.55 \%$ & $27.9 \%$ & $25.55 \%$ \\
\hline
\end{tabular}



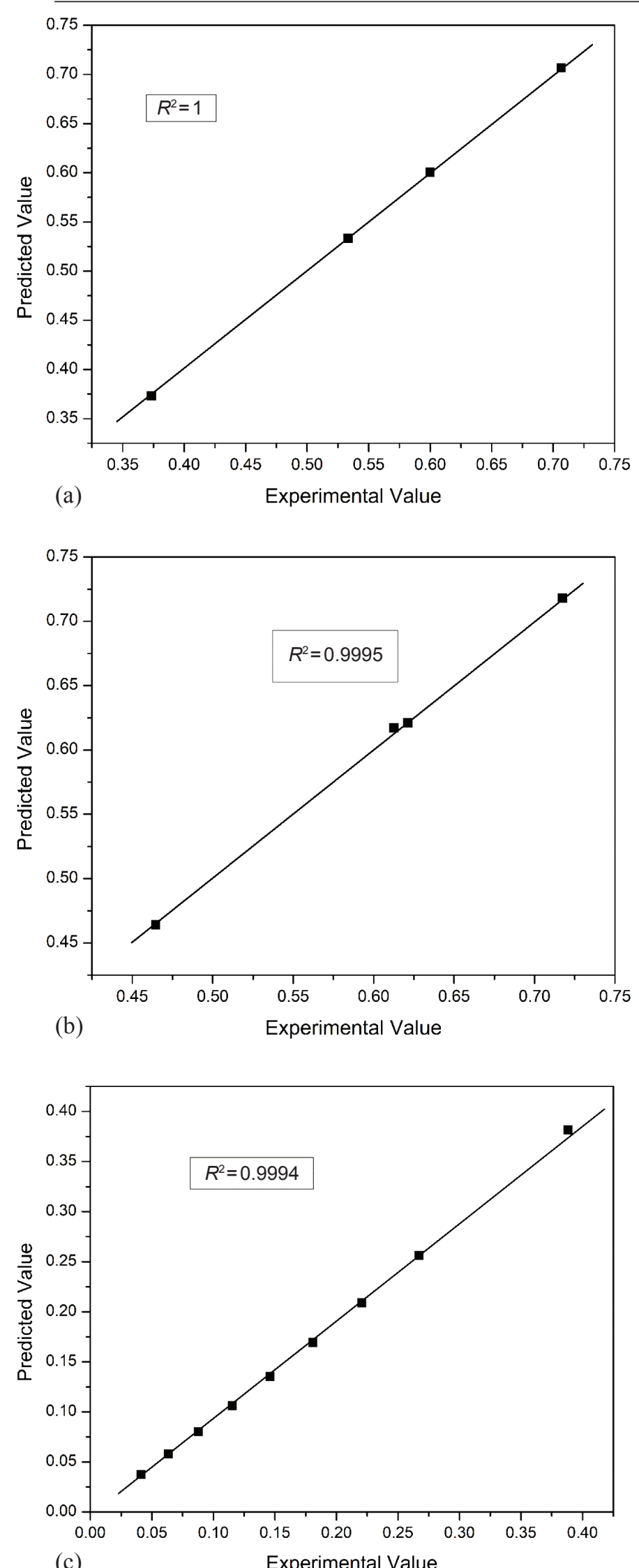

(c)

Experimental Value

Fig. 6 - (a) Comparison of the test samples for E using ANN model, (b) Comparison of the test samples for $\ln A$ using ANN model, (c) Comparison of the test samples for $n$ using ANN model
Kinetics of pure PC is best described by chemical process, $F n$ mechanism, where $n$ is 1 , whereas, kinetics of $3 \%$ polymer composite is best described by chemical process, $F_{3 / 2}$ mechanism. Lower values of $\ln A$ in the range $10^{6}$, indicates a tight complex or a surface reaction. Higher values of $\ln A$ indicate a loose complex, as is the case with polymer composites. A different mechanism acquired by polymer composites indicates different behavior of composites as compared to pure PC. The higher values of kinetic parameter were observed for polymer composites. It was observed that the dependence of $\ln A$ on $E$ is somewhat linear, also known as the kinetic compensation effect. It was also observed that lower entropy corresponds to higher $E$ values. Thus, the use of model-free and modelistic methods leads to the better understanding of kinetics of polymer composites degradation. Hence, it is possible to design a reactor for degradation of $\mathrm{PC}$ and its composites to obtain synthetic gas and low molecular weight hydrocarbons. The application of artificial neural network supported in designing models that could be applied to determine kinetic parameters independently based on actual data and not regression fit alone, without carrying out a number of experiments, would result in saving time and money.

\section{ACKNOWLEDGEMENTS}

The authors would like to thank the Ministry of Human Resource Development (MHRD) for the continuing financial support. We also wish to thank Anton Paar India Pvt. Ltd., Haryana, for extending the help needed for tribological study. We are grateful for their devoted time in testing the samples for coefficient of friction.

\section{FUNDING}

The authors would like to thank Human Resource Development (MHRD) for the continuing financial support.

\section{DISCLOSURE OF POTENTIAL CONFLICTS OF INTEREST}

The authors would like to declare that they have no conflict of interest.

\section{OWNERSHIP}

Authors declare that the submitted work is our own, and that copyright has not been breached in seeking its publication.

\section{ORIGINALITY}

Authors declare that the submitted work has not previously been published in full and is not being considered for publication elsewhere. 


\section{Supplementary table}

Table S 1 - Dataset for generating the ANN model

\begin{tabular}{|c|c|c|}
\hline Conversion $(\alpha)$ & Temperature (K) & Time (min) \\
\hline 0.1 & 710 & 87.4 \\
\hline 0.2 & 723 & 90.0 \\
\hline 0.25 & 728 & 91.0 \\
\hline 0.3 & 732 & 91.8 \\
\hline 0.35 & 736 & 92.6 \\
\hline 0.4 & 739 & 93.2 \\
\hline 0.45 & 743 & 94.0 \\
\hline 0.5 & 746 & 94.6 \\
\hline 0.55 & 750 & 95.4 \\
\hline 0.6 & 754 & 96.2 \\
\hline 0.65 & 764 & 98.2 \\
\hline 0.1 & 720 & 44.7 \\
\hline 0.15 & 728 & 45.5 \\
\hline 0.2 & 735 & 46.2 \\
\hline 0.25 & 741 & 46.8 \\
\hline 0.35 & 749 & 47.6 \\
\hline 0.4 & 754 & 48.1 \\
\hline 0.45 & 758 & 48.5 \\
\hline 0.5 & 762 & 48.9 \\
\hline 0.55 & 765 & 49.2 \\
\hline 0.6 & 770 & 49.7 \\
\hline 0.65 & 775 & 50.2 \\
\hline 0.1 & 737 & 30.9 \\
\hline 0.15 & 745 & 31.5 \\
\hline 0.2 & 751 & 31.9 \\
\hline 0.25 & 754 & 32.1 \\
\hline 0.3 & 759 & 32.4 \\
\hline 0.35 & 762 & 32.6 \\
\hline 0.4 & 766 & 32.9 \\
\hline 0.45 & 769 & 33.1 \\
\hline 0.55 & 776 & 33.5 \\
\hline 0.6 & 780 & 33.8 \\
\hline 0.65 & 785 & 34.1 \\
\hline 0.1 & 743 & 23.5 \\
\hline 0.15 & 751 & 23.9 \\
\hline 0.2 & 758 & 24.2 \\
\hline 0.25 & 763 & 24.5 \\
\hline 0.3 & 768 & 24.7 \\
\hline 0.35 & 772 & 24.9 \\
\hline 0.4 & 775 & 25.1 \\
\hline 0.45 & 778 & 25.2 \\
\hline 0.5 & 782 & 25.4 \\
\hline 0.55 & 785 & 25.6 \\
\hline 0.65 & 794 & 26.0 \\
\hline
\end{tabular}

\section{References}

1. news.ihsmarkit.com. (13. 1. 2016).

2. Feng, J., Hao, J., Du, J., Yang, R., Using TGA/FTIR TGA/ MS and cone calorimetry to understand thermal degradation and flame retardancy mechanism of polycarbonate filled with solid bisphenol A bis(diphenyl phosphate) and montmorillonite, Polym. Degrad. Stab. 97 (2012) 605. doi: https://doi.org/10.1016/j.polymdegradstab.2012.01.011

3. Sonawane, S. S., Mishra, S., Shimpi, N. G., Effect of nano- $\mathrm{CaCO}_{3}$ on mechanical and thermal properties of polyamide nanocomposites, Polym. Plast. Technol. Eng. 49 (2009) 38. doi: https://doi.org/10.1080/03602550903204220

4. Mishra, S., Sonawane, S. S., Shimpi, N. G., Influence of organo-montmorillonite on mechanical and rheological properties of polyamide nanocomposites, Appl. clay Sci. 46 (2009) 222.

doi: https://doi.org/10.1016/j.clay.2009.07.024

5. Charde, S. J., Sonawane, S. S., Rathod, A. P., Sonawane, S. H., Shimpi, N. G., Parate, V. R., Copper-doped zinc oxide nanoparticles: Influence on thermal, thermo mechanical, and tribological properties of polycarbonate, Polym. Compos. (2017). doi: https://doi.org//10.1002/pc.24315

6. Kim, H. T., Oh, S. C., Kinetics of thermal degradation of waste polypropylene and high-density polyethylene, J. Ind. Eng. Chem. 11 (2005) 648.

7. Gersten, J., Fanber, G. V., Hetsroni, G., Shindler, Y., Kinetic study of the thermal decomposition of polypropylene, oil shale, and their mixture, Fuel 79 (2000) 1679. doi: https://doi.org/10.1016/S0016-2361(00)00002-8

8. Kaci, M., Djidjelli, H., Boukerrou, A., Zaidi, L., Effect of wood filler treatment and EBAGMA compatibilizer on morphology and mechanical properties of low density polyethylene/olive husk flour composites, Express Polym. Lett. 1 (2007) 467. doi: https://doi.org/10.3144/expresspolymlett.2007.65

9. Ballice, L., Reimert, R., Classification of volatile products from the temperature-programmed pyrolysis of polypropylene (PP), atactic-polypropylene (APP) and thermogravimetrically derived kinetics of pyrolysis, Chem. Eng. Process. 41 (2002) 289. doi: https://doi.org/10.1021/ef0002041

10. Marcilla, A., Gómez, A., Reyes-Labarta, J. A., Giner, A., Hernandez, $F$., Kinetic study of polypropylene pyrolysis using ZSM-5 and an equilibrium fluid catalytic cracking catalyst, J. Anal. Appl. Pyrol. 68-69 (2003) 467. doi: https://doi.org/10.1016/S0165-2370(03)00036-6

11. Filho, J. G. A. P., Graciliano, E. C., Silva, A. O. S., Souza, M. J. B., Araujo, A. S., Thermo gravimetric kinetics of polypropylene degradation of ZSM-12 and ZSM-5 catalysts, Catal. Today 107-108 (2005) 507. doi: https://doi.org/10.1016/j.cattod.2005.07.065

12. Durmus, A., Koç, S. N., Pozan, G. S., Kasgoz, A., Thermalcatalytic degradation kinetics of polypropylene over BEA, ZSM-5 and MOR zeolites, Appl. Catal. Part B Environ. 61 (2005) 316. doi: https://doi.org/10.1016/j.apcatb.2005.06.009

13. Peterson, D. J., Vyazovkin, S., Wight, C. A., Kinetics of the thermal and thermo-oxidative degradation of polystirene, polyethylene and poly(propylene), Macromol. Chem. Phys. 202 (2001) 775. doi: https://doi.org/1022-1352/2001/0603-0775 
14. Song, R., Jiang, Z., Bi, W., Cheng, W., Lu, J., Huang, B., Tang, $T$., The combined catalytic action on solid acids with nickel for the transformation of polypropylene into carbon nanotubes by pyrolysis, Chem. Eur. J. 13 (2007) 3234. doi: https://doi.org/10.1002/chem.200601018

15. Apaydin-varol, E., Polat, S., Putun, A. E., Pyrolysis kinetics and thermal decomposition behavior of polycarbonate - a TGA-FTIR study, Thermal Science 18 (2014) 833. doi: https://doi.org/10.2298/TSCI1403833A

16. Zhou, L., Luo, T., Huang, Q., Co-pyrolysis characteristics and kinetics of coal and plastic blends, Energy Convers. Manag. 50 (2009) 705. doi: https://doi.org/10.1016/j.enconman.2008.10.007

17. Singh, S., Wu, C., Williams, P. T., Pyrolysis of waste materials using TGA-MS and TGA-FTIR as complementary characterization techniques, J. Anal. Appl. Pyrolysis Mar (2012) 99 . doi: https://doi.org/10.1016/j.jaap.2011.11.011

18. Bozi, J., Czegeny, Z., Meszaros, E., Blazso, M., Thermal decomposition of flame retarded polycarbonates, J. Anal. Appl. Pyrol. 79 (2007) 337. doi: https://doi.org/10.1016/j.jaap.2007.01.001

19. Vyazovkin, S., Sbirrazzuoli, N., Isocoversional kinetics of thermally stimulated processes, Macromol. Rapid. Commun. 27 (2006) 1515.

doi: https://doi.org/10.1002/marc.200600404

20. Cai, J., Wu, W., liu, R., Isoconversional kinetics analysis of complex solid state processes: Parallel and successive reactions, Ind. Eng. Chem. Res. 51 (2012) 16157. doi: https://doi.org/10.1021/ie8018615

21. Opfermann, J., Kinetic analysis using multivariate non-linear regression. I. Basic concepts, J. Therm. Anal. Calorim. $60(2000) 641$.

doi: https://doi.org/10.1023/A:1010167626551

22. Chrissafis, K., Complementary use of isoconversional and model-fitting methods, J. Therm. Anal. Calorim. 95 (2009) 273. doi: https://doi.org/10.1007/s10973-008-9041-z

23. Cadenato, A., Moramcho, J., Fernandez-Francos, X., Salla, $J$., Ramis, $X$., Comparative kinetic study of the non-isothermal curing of bis-GMA/TEGDMA systems, J. Therm. Anal. Calorim. 89 (2007) 233. doi: https://doi.org/10.1007/s10973-006-7567-5

24. Zhang, Z., Klein, P., Frederich, K., Dynamic mechanical properties of PTFE based short carbon fibre reinforced composites: Experiment and artificial neural network prediction, Compos. Sci. Technol. 62 (2002) 1001. doi: https://doi.org/10.1016/S0266-3538(02)00036-2

25. Zhang, Z., Frederich, K., Artificial neural networks applied to polymer composites: A review, Compos. Sci. Technol. 63 (2003) 2029. doi: https://doi.org/10.1016/S0266-3538(03)00106-4

26. Jones, S. P., Jansen R., Fusaro, R. L., Preleminary investgation of neural network techniques to predict tribological properties, Tribol. Trans. 40 (1997) 312. doi: https://doi.org/10.1080/10402009708983660

27. Sánchez-Jiménez, P. E., Pérez-Maqueda, L. A., Perejón, A., Criado, J. M., A new model for the kinetic analysis of thermal degradation of polymers driven by random scission, Polym. Degrad. Stab. 95 (2010) 733.

doi: https://doi.org/10.1016/j.polymdegradstab.2010.02.017

28. Sarve, A., Sonawane, S. S., Varma, M. N., Ultrsound assisted biodiesel production from sesame (Sesamum indicum L.) oil using barium hydroxide as a heterogenous catalyst: Comparative assessment of prediction abilities between response surface methodology (RSM) and artificial neural network. Ultrason. Sonochem. 26 (2015) 218. doi: https://doi.org/10.1016/j.ultsonch.2015.01.013
29. Sbirrazzuolo, N., Brunel., Neural, D., Computational neural networks for mapping calorimetric data: Application of feed-forward neural networks to kinetic parameters determination and signla filtering, Neural Comput. Appl. 5 (1997) 20. doi: https://doi.org/10.1007/BF01414100

30. Bezzera, E. M., Bento, M. S., Rocco, J. A. F. F., Iha, K., Laurenco, V. L., Pardini, L. C., Artificial neural network (ANN) prediction of kinetic parameters of (CRFC) composites, Comput. Mater. Sci. 44 (2008) 656. doi: https://doi.org/10.1016/j.commatsci.2008.05.002

31. Sunphorka, S., Chalermsinsuwan, B., Piumsomboon, P., Application of artificial neural network for kinetic parameters prediction of biomass oxidation from biomass properties, J. Energy Inst. 90 (2015) 51. doi: https://doi.org/10.1016/j.joei.2015.10.007

32. Lingaraju, D., Ramji, K., Mohan Rao, N. B. R., Laxmi, $U$. R., Characterization and prediction of some engineering properties of polymer-clay/silica hybrid nanocomposites through ANN and regression models, Proceedia Eng. 10 (2011) 9 . doi: https://doi.org/10.1016/j.proeng.2011.04.004

33. Muravyev, N. V., Pivkina, A. N., New concept of thermokinetic analysis with artificial neural networks, Thermochim. Acta 637 (2016) 69. doi: https://doi.org/10.1016/j.tca.2016.05.018

34. Koga, N., Sestak, J., Kinetic compensation effect as a mathematical consequence of the exponential rate constant, Thermochim. Acta 182 (1991) 201. doi: https://doi.org/10.1016/0040-6031(91)80005-4

35. Charde, S. J., Sonawane, S. S., Sonawane, S. H., Navin, S., Influence of functionalized calcium carbonate nanofillers on the properties of melt-extruded polycarbonate composites, Chem. Eng. Commun. 205 (2018) 492. doi: https://doi.org/10.1080/00986445.2017.1404459

36. Vlaev, L. T., Markovska, I. G., Lyubchev, L. A., Non-isothermal kinetics of pyrolysis of rice husk, Thermochim. Acta 406 (2003) 1. doi: https://doi.org/10.1016/S0040-6031(03)00222-3

37. Albano, C. L., Sciamanna, R., Aquino, T., Martínez, J. J., Methodology to evaluate thermogravimetric data using computational techniques in the polymer field, European Congress on Computational Methods in Applied Science and Engineering, ECCOMAS 2000, Barcelona, Spain 1114 Sept., 2000, 1.

38. Roy, P. K., Surekha, P., Rajagopa, C., Choudhary, V., Thermal degradation studies of LDPE containing cobalt stearate as pro-oxidant, Express Polym. Lett.1 (2007) 208. doi: https://doi.org/10.3144/expresspolymlett.2007.32

39. Vlaev, L. T., Georgieva, V. G., Genieva, S. D., Products and kinetics of non - isothermal decomposition of vanadium(IV) oxide compounds, Journal of Thermal Analysis and Calorimetry 88 (2007) 805. doi: https://doi.org/10.1007/s10973-005-7149-y

40. Kissinger, H. E., Reaction kinetics in differential thermal analysis, Anal. Chem. 11 (1957) 1702. doi: https://doi.org/10.1021/ac60131a045

41. Sestak, J., Study of kinetics of the mechanism of solid-state reactions at increasing temperatures, Thermochim. Acta 3 (1971) 1 doi: https://doi.org/10.1016/0040-6031(71)85051-7

42. Chen, $Y$., Wang, $Q$., Thermal oxidative degradation kinetics of flame retarded polypropylene with intimescent flame retardant master batches in situ prepared in twin screw extruder, Polym. Degrad. Stab. 92 (2007) 280. doi: https://doi.org/10.1016/j.polymdegradstab.2006.11.004 
43. Zhang, F., Zhang, J., Wang, Y., Modeling study of the combustion of intumescent fire retardant polypropylene, Express Polym. Lett. 1 (2007) 157. doi: https://doi.org/10.3144/expresspolymlett.2007.25

44. Coats, A. W., Redfern, J. P., Kinetic parameters for thermogravimetric data, Nature 201 (1964) 68. doi: https://doi.org/10.1038/201068a0

45. Madhysudanan, P. M., Krishnan, K., Ninan, K. N., New equations for kinetic analysis of non-isothermal reactions, Thermochim. Acta 221 (1993) 13. doi: https://doi.org/10.1016/0040-6031(93)80519-G

46. Tang, W., Liu, Y., Zang, H., Wang, C., New approximate formula for Arrhenius temperature integral, Thermochim. Acta 408 (2003) 39.

doi: https://doi.org/10.1016/S0040-6031(03)00310-1

47. Turmanova, S. C., Genieva, S. D., Dimitrova, A. S., Vlaev, L. T., Non-isothermal degradation kinetics of filled with rise husk ash polypropene composites, eXPRESS Polymer Letters 2 (2008) 133.

doi: https://doi.org/10.3144/expresspolymlett.2008.18

48. Carrion, F. J., Arribas, A., Bermudez, M. D., Guillamon, A., Physical and tribological properties of a new polycarbonate-organoclay nanocomposite, Eur. Polym. J. 44 (2008) 968 .

doi: https://doi.org/10.1016/j.eurpolymj.2008.01.038

49. Vasconcelas, G. C., Mazur, R. L., Ribeiro, B., Botelho, E. C., Costa, M. L., Evaluation of decomposition kinetics of poly ether ether ketone by thermogravimetric analysis, Mater. Res. 17 (2014) 227.

doi: https://doi.org/10.1590/S1516-14392013005000202

50. Quan, C. A., Li, A., Gao, N., Thermo gravimetric analysis and kinetic study on large particles of printed circuit board wastes, Waste Manag. 29 (2009) 2353. doi: https://doi.org/10.1016/j.wasman.2009.03.020

51. Ruvolo-Filho, A., Curti, P. S., Chemical kinetic model and thermodynamic compensation effect of alkaline hydrolysis of waste poly(ethylene terephthalate) in nonaqueous ethylene glycol solution, Ind. Eng. Chem. Res. 45 (2006) 7985. doi: https://doi.org/10.1021/ie060528y

52. Matlab neural network toolbox, http://www.mathworks. com/ products/ neural-network (2016).

53. Khanam, P. N., AlMaadeed, M. A., AlMaadeed, S., Kunhoth, S., Ouederni, M., Sun, D., Hamilton, A., Jones, E. H., Mayoral, B., Optimization and prediction of mechanical and thermal properties of Graphene/LLDPE nanocomposites by using Artificial Neural Network, Int. J. Polym. Sci. 2016 (2016) 1. doi: https://doi.org/10.1155/2016/5340252

54. Jain, A. K., Mao, J., Mohiuddin, K. M., Artificial neural networks: A tutorial, Computer (Long. Beach. Calif). 29 (1996) 31 doi: https://doi.org//10.1109/2.485891. 